\title{
Estar lá, Escrever lá
}

\author{
FÁTIMA CECCHETTO
}

\begin{abstract}
WACQUANT, Loïc J. D. Corpo e Alma: notas etnográficas de um aprendiz de boxe. Rio de Janeiro: Relume Dumará. 293 p.
\end{abstract}

Publicado na íntegra 12 anos depois de uma primeira aterrissagem no terreno do boxe, Corpo e Alma: notas etnográficas de um aprendiz de boxe, de Löic Wacquant, é um livro instigante. Instigante pelo modo como o autor nos conduz a uma viagem pelo mundo do boxe e pelas sensações corporais produzidas por sua prática.

Nesse livro, Wacquant se vale de vários aportes originais. Adota como ponto de partida na pesquisa sobre os lutadores de boxe o "aprendizado pelo corpo" da ordem social. O trabalho também conduz o leitor por intrincado labirinto de reflexões sobre a construção social da masculinidade e da virilidade entre os boxeadores, e de seus pressupostos teóricos e práticos. Discípulo de Pierre Bourdieu, ele há muito vem lançando seu olhar sobre os homens que entram nessa sangrenta mas gloriosa profissão, desvelando algumas das particularidades do habitus pugilista (Wacquant,1998) ${ }^{2}$.

Conhecido por seus trabalhos pioneiros sobre a juventude pobre em vários países, Wacquant é atualmente professor de sociologia da Universidade da Califórnia, Berkeley, e pesquisador do Centre de Sociologie Européenne du College de France. Seus principais temas de trabalho incluem: marginalidade urbana, relações raciais, violência e estudos sobre instituições penitenciárias. Possui trabalhos publicados no Brasil, como Prisões da miséria (Jorge Zahar, 2001), Punir os pobres (Freitas Bastos, 2001), Os condenados da cidade (Revan, 2001). Integra ainda a coletânea $A$ miséria do mundo (Vozes, 1997), sob a direção de Pierre Bourdieu, com o artigo "A zona".

O presente trabalho, de predominância narrativa, integra análise sociológica e relato, conceito e descrição do cotidiano do boxeador. O livro tem seu 
mérito pela riqueza do material coletado: foram duas mil e trezentas páginas de notas sobre o mundo do boxe. Embora o autor goste de frisar tratar-se do primeiro relato, que poderá ser seguido de uma segunda obra mais explicitamente teórica, esse livro de Wacquant é inequivocamente uma referência para quem se dedica ao campo tradicionalmente denominado etnografia urbana.

Os argumentos gerais do livro estão sistematizados no prefácio e no prólogo. Ali encontram-se os principais pontos teóricos e metodológicos, que são detalhados nos três textos subseqüentes (1- A rua e o ringue, 2- Uma noitada no Studio 104 e 3) "Busy Louie" nas Golden Gloves), que passam por três eixos centrais: a) os impasses da conversão moral e sensual ao cosmos pugilístico; b) a compreensão do ofício de boxeador; c) os questionamentos impostos pela sua inserção num clube de boxe de um bairro do gueto negro de Chicago.

Quanto à sua entrada no campo, Wacquant afirma no prefácio que sua "aventura" de fato começou em 1988, quando procurava um ponto de observação mais acurado que permitisse tocar de perto a realidade cotidiana do gueto, uma investigação que desenvolvia na Universidade de Chicago, em colaboração com William Julius Wilson ${ }^{3}$, pesquisador negro de origem norteamericana que se dedicou a estudar, no final dos anos 80, o agravamento das condições sociais do subproletariado negro residente nas áreas pobres da cidade. A colaboração com Wilson abrangia o exame das estratégias sociais utilizadas pelos jovens negros do gueto, objeto original da pesquisa. Talvez por causa disso, Wacquant descreva de modo contundente o "acaso" de sua chegada à academia de boxe, situada no bairro de Woodlawn, "um lugar precário e degradado", levado por um amigo francês e judoca da universidade.

Dessa "janela", porém, o autor enxerga a oportunidade de questionar o que chama de visão do gueto como um universo "desorganizado", e lembra que o falso conceito underclass é analiticamente insuficiente para se compreender a realidade do gueto. Insuficiente porque, sob essa marca degradante, estariam circunscritas, de modo indistinto, pessoas em situações muito diferentes, como beneficiários da assistência social, desempregados de longo termo, mães solteiras, famílias monoparentais, criminosos, membros das gangues, drogados e sem-teto. Além disso, o termo, ao focalizar apenas a ecologia dos bairros pobres e as características individuais de seus habitantes, confunde mas que esclarece o exame da situação social de degradação contínua das classes mais marginalizadas da América pós-fordista, do mes- 
mo modo que permite comodamente encobrir a dominação branca e a imperícia das autoridades do front social e urbano (p. 13).

O desafio de aprender um esporte, dentre todos considerado o mais exigente, e ao mesmo tempo ser capaz de retraduzir essa compreensão dos sentidos em linguagem sociológica, dentro de formas expressivas adequadas, sem minimizar suas particularidades mais distintivas, foram alguns dos percalços também anotados pelo autor, sublinhando a maneira decisiva como influenciaram no desenvolvimento dessa experiência etnográfica. No entanto, também constituem a possibilidade de realizar uma sociologia do boxe. Como observa, "tudo deve ser feito para escapar ao objeto pré-construído, ao exotismo pré-fabricado da profissão, seus mitos de heró́smo e ascensão social, tão presentes na mitologia sobre as lutas, que trazem a ameaça de excesso de sociologia espontânea" (p. 22). Por isso, o objetivo de Wacquant nesse trabalho foi apreender a lógica social e sensual que informa o boxe, pelo seu lado menos conhecido e espetacular, percorrendo os ritos ínfimos e íntimos da vida do gym, atividade levada a cabo pelo pesquisador inserindo-se na realidade nativa com a qual se confrontou. Durante três anos, Wacquant integrou uma equipe na academia, iniciando-se nos rudimentos do ofício de boxeador, onde cultivou relações de amizade com treinadores e boxeadores do lugar, observando in vivo a gênese social e o desenvolvimento das carreiras pugilísticas.

Para adentrar naquele espaço marcadamente negro (e masculino), foi indispensável um processo de negociação lento e cuidadoso, admite o autor. Sua condição de único (homem) branco, criado em uma família de classe média de uma pequena cidade do sul da França, o fez imaginar que jamais ganharia a confiança dos freqüentadores de Woodlawn para estudá-los, se não fossem três aspectos compensadores que atuaram para sua penetração no mundo social dos pugilistas:

1. o ethos igualitarista dado pelo que chama de daltonismo racial da cultura pugilística: para nele ser aceito totalmente, deve-se antes de mais nada "dobrar-se" à disciplina comum, pagando (com o corpo) o que era devido no ringue;

2. sua nacionalidade francesa concedeu-lhe uma espécie de exterioridade estatutária, que atuou como uma linha de fuga em relação às relações de desprezo e de desconfiança que opõem brancos e negros na América do Norte. Contou a seu favor o capital histórico de simpatia de que a França desfruta entre a população afro-americana, atesta Wacquant;

3. sua hexis corporal, que o afasta do americano branco médio (sic), the 
abriu as portas do clube de boxe, pois, como anotou seu treinador, dando ênfase à sua perícia no ringue, apesar da procedência caucasiana,"você é feito eles [os negros]" (p. 27). Contava a favor de si, porém, o fato de ter praticado esportes competitivos na infância, o que o dotou de um capital social esportivo indispensável para enfrentar com sucesso as provas e o aprendizado do boxe dentro das regras da Nobre Arte.

Para compreender o ofício do boxeador, o desafio e a proposta que Wacquant se coloca são, em primeiro lugar, tematizar o corpo, não apenas de uma posição distanciada, mas partindo do próprio corpo como instrumento de investigação e vetor de conhecimento. Nesse empreendimento, o autor lança mão da noção operativa de habitus, um dos conceitos centrais que preside a obra de Marcel Mauss (1974), desenvolvido anos mais tarde por Pierre Bourdieu, autor que irá ressaltar mais a questão do habitus (ou hexis) como uma forma pré-reflexiva de o corpo introjetar as experiências do mundo, transmutando-se numa "política incorporada". Desse modo, Wacquant situa o boxe tanto como uma técnica corporal, resultado das montagens biopsicossociais dos atos mais ou menos habituais na vida do indivíduo e na história da sociedade, quanto como uma "disposição incorpo$\mathrm{rada}^{4}$. Para Wacquant, pôr fisicamente em jogo o corpo nessa investigação foi uma dimensão enriquecedora, que permitiu ainda novas possibilidades interpretativas.

Desse lugar o autor propõe a conversão ao ethos pugilístico. A única possibilidade de penetrar no cotidiano sensual e moral do lutador comum é imbricar-se estreitamente a seus esquemas mentais e mecanismos práticos, que emergem dos confrontos corporais. Esse movimento incluiu o que chamou de "deitar-se nas cordas", como rezam as praxes do métier. De modo enfático, o autor menciona esse processo, no qual deixou-se "encorpar" pelas técnicas do boxe, isto é, colocando-se a serviço de "uma prática tão intensamente corporal, uma cultura totalmente cinética no qual o mais essencial transmite-se, adquire-se e desdobra-se aquém da linguagem e da consciência" (p. 15).

Antecipando seu aprendizado como "perfeito noviço" (convertido), o autor menciona como seu dever de iniciante a aquisição de socos sem reclamações, mas o prazer carnal de se exercitar com amigos quase o fez "largar tudo" para passar mais tempo com seus parceiros do clube de boxe. Pelo que diz, chegou a pensar em interromper a carreira universitária para ficar mais tempo ao lado de seus novos pares e em companhia de seu técnico, Dee Dee Armour, descrito como um segundo pai. Nesse processo de 
legitimação contínua, o autor se abandonou às exigências do campo, o que lhe valeu a estima de seus camaradas de clube e o apelido de Busy Louie, uma espécie de brincadeira com seu estilo ágil, que se transformou no nome de guerra no meio pugilístico. E fez mais. Em sua vivência no esporte, pouco a pouco foi gostando do jogo, a ponto de dedicar todas as suas tardes a permanecer na academia, onde "calçou as luvas" e passou para o lado de "dentro" do ringue. O exercício de reflexão sobre o boxe se faz a partir desse plano.

Apesar das recomendações do autor de que o livro pode ser percorrido sem grandes preocupações analíticas, ser "pensado segundo princípios de vasos comunicantes" (sic), os três textos precisam ser lidos com bastante atenção para se desvendar um mundo curiosamente tortuoso.

No primeiro, "A rua e o ringue", o mais denso, o autor articula três níveis de discussão, bastante imbricados, para demonstrar a aquisição da aprendizagem do esporte: 1) as representações sobre o mundo do boxe, suas "leis" e suas "promessas"; 2) a regulação da violência, a cultura da rua e a masculinidade; 3) A "gestão" do corpo do boxeador, enquanto uma pedagogia visual e mimética.

Para descrever como se dá o trabalho de conversão ginástica, perceptiva, emocional e mental do boxeador na sociedade norte-americana contemporânea, o autor retoma Émile Durkheim para abordar o boxe como uma escola de moralidade, isto é, como "uma máquina de fabricar o espírito de disciplina, indispensável à eclosão da vocação pugilística (p. 32). Assim, desde logo, afirma ser o habitus pugilístico uma empresa que se funda sobre uma dupla antinomia: uma atividade que parece situar-se na fronteira entre natureza e cultura mas que exige uma gestão quase racional do corpo e do tempo de modo muito complexo. Outra contradição diz respeito ao boxe ser um esporte extremamente individual, mas que não põe só em causa o indivíduo, sendo obra da razão prática coletiva e individual. Parafraseando seu mestre Bourdieu, lembra a importância do esporte como uma prática corporal que encerra um conjunto de questões teóricas de primeira importância, pois "o esporte é, junto com a dança, um dos terrenos em que se coloca com acuidade máxima o problema das relações entre a teoria e a prática, e também entre a linguagem e o corpo" (p. 34).

Seguindo nesse primeiro plano, a investigação de Wacquant passa pela constatação de que não é possível imaginar que somente as frações mais deserdadas do subproletariado negro do gueto sejam recrutadas para o gym, no sentido dado a underclass no "préfácio", mas que o pugilista é prove- 
niente da classe operária local. Uma contribuição importante desse estudo é mostrar como é necessária alguma integração socioeconômica para levar a cabo o regime e a moral do treinamento exigidos para obter tal aprendizado. $\mathrm{O}$ autor assegura como fundamental uma boa dose de ascetismo físico e mental para enfrentar os desafios do esporte, pendor que os jovens saídos das famílias mais despossuídas têm de desenvolver para ganhar competência esportiva, sob a pena de serem sumariamente eliminados pelos treinadores, os verdadeiros senhores dos templos pugilísticos. Paradoxalmente, as "leis" da disciplina espartana do boxe penitenciam severamente os mais excluídos. Em suma, contrariando a mitologia coletiva sobre os lutadores como seres situados nas escalas mais baixas da hierarquia social, a análise de Wacquant mostrou que o perfil socioeconômico dos pugilistas profissionais é mais elevado que o do segmento mais empobrecido da população masculina do gueto.

Num segundo plano, são discutidos alguns dos princípios que organizam o complexo de atividades que é o boxe na sociedade americana, trazendo à luz, principalmente, a regulação da violência que se opera no interior e ao redor do salão de treinamento. Nessa linha, o autor enumera ainda algumas razões da escolha do esporte pelos jovens do gueto. Segundo "suas promessas", as principais seriam: 1) autodefesa, 2) a sociabilidade protegida e 3) a escapatória à criminalidade. Desde cedo acostumados com as formas mais variadas e mais imprevisíveis da cultura da rua, treinar boxe, para os garotos, exprime uma ligação com a violência da rua: a academia passa a ser um espaço onde se pode dar provas de excelência no manejo do capital cultural próprio ao grupo. No entanto, dentro do salão essa habilidade é constrangida pela interiorização das regras internas de regulação da violência interpessoal, comparável pelos seus seguidores ao engajamento no Exército.

Ainda nesse plano, o autor sugere ver o boxe como possível vetor de "desbanalização" da vida cotidiana do gueto, porque, por meio da modelagem do corpo e das emoções, ele atuaria no sentido de acionar o gosto pela aventura e pelo exercício da liberdade individual. Um espaço onde possam se reunir, sob o signo do prestígio e da honra masculina, jovens que não esperam muito do mundo que os espreita lá fora, que é o das atividades e redes constitutivas da economia do tráfico do bairro. A afiliação ao clube representa um meio de acesso a um universo distintivo, sobretudo como escapatória da carreira criminosa. Embora o autor não faça referência explícita ao tratamento que Norbert Elias dá às configurações da violência no con- 
texto esportivo, o clube pode ser visto como lugar que converge para pacificar o comportamento de seus membros, um local para o exercício da violência controlada e construtiva, contrastando com a violência sem razão dos confrontos imprevistos, sem limites e sem sentido das gangues da rua.

Assim, uma das funções do boxe anotadas pelo autor seria ligar a rua ao ringue, numa dupla relação de simbiose e de oposição. Isto porque o clube de boxe parece desempenhar papel de escudo contra a insegurança do gueto e as pressões da vida cotidiana, proporcionando a sociabilidade protegida, mas que se encontra ligada à dura realidade de modo inextricável. No entanto, o clube seria também um ambiente deflagrador de práticas ou formas de interação social anódinas, ou seja, aqueles processos puros de associação, que, no limite, excluem todo tema "sério" das conversas, em nome da sociabilidade, tal como definido por George Simmel, como uma forma lúdica de socialização. De acordo com Wacquant, a sociabilidade do gym, aparentemente desprovida de conteúdo, expressa as categorias de entendimento em vigor no universo pugilístico, noções que, por sua vez, ancoram a cultura masculina da rua: uma combinação das qualidades viris da coragem física, da solidariedade com o grupo e da desconfiança individualista (p. 59). Com esta caracterização, o autor chama atenção para o grau de influência e de importância do grupo de pares masculinos no indivíduo e obviamente também da relação deste com o referido grupo. O clube de boxe é um dos últimos refúgios para perpetuação da subcultura masculina na sociedade americana contemporânea.

Desse modo, a construção da masculinidade também é objeto de inquirição quando Wacquant sublinhar o boxe como um terreno para pôr em ação os valores centrais da masculinidade: "ele é para os homens, sobre os homens, ele é os homens (p. 69). Quanto às mulheres na academia, uma nota de pé de página (n. 26) é particularmente iluminadora da posição feminina naquele ambiente: "um gênero fisicamente ausente, mas simbolicamente onipresente em negativo (grifo nosso) na academia, assim como no universo pugilístico", oferece-nos a justa medida de um impasse colocado por essa etnografia sobre os homens lutadores, que passa pelo entendimento do caráter eminentemente relacional da construção da identidade masculina. Pelo que nos apresenta Wacquant, não teria sido possível para uma mulher realizar imersão tão demorada nesse ambiente, o gênero/sexo do pesquisador contou muito para a inserção neste campo. Sua etnografia está centrada justamente no gênero do pesquisador e se concretizou a partir desse lugar. Pois, nas taxonomias homem/mulher, presentes no circuito, segundo nos 
apresenta Wacquant, as masculinidades não se "descolam" dos homens, por exemplo. $\mathrm{O}$ foco nas relações de gênero não foi o objetivo do autor nesse trabalho, ainda que nas hierarquizações pugilísticas, surgidas na academia a partir de critérios de idade, etnicidade e posição de classe dos lutadores, bem documentadas no trabalho, forneçam pistas para elucidar um sistema classificatório da masculinidade no local. No entanto, parece que há um limite, colocado pelo material empírico em si, no qual um único modelo de masculinidade, a saber, o da masculinidade heterossexual do boxeador negro e pobre do gueto, pôde ser examinado. Esse modelo, ancorado em normas masculinas essenciais da força física, da responsabilidade e da coragem, pelo que sugerem as reflexões de Wacquant, excluiria outras dimensões da subjetividade e da sexualidade masculina, dadas as pressões sociais a que estão expostos, contribuindo para levá-los a uma forma rígida de masculinidade.

Não é fácil escrever sobre os boxeadores sem esbarrar em estereótipos sobre sua "natureza selvagem", e esse é um dos pontos altos do livro: a forma como Wacquant vai montando episódios que trazem depoimentos desses homens que sacrificam seus corpos oferecem as categorias de julgamento que ordenam o mundo dos afetos e dos desejos dos lutadores entrelaçados à possibilidade de ascensão social - da exclusão e da pobreza ao estrelato, freqüentemente efêmero, mas que ainda assim os instiga a uma vida diferente. A partir de dados etnográficos detalhados, Wacquant descreve, em terceiro plano, a apropriação, por impregnação progressiva, de um conjunto de mecanismos corporais e de esquemas mentais que informa $\mathrm{o}$ boxe como ofício do corpo, para além de sua descrição como esporte puramente bárbaro.

Diante das questões que dão ao capítulo sua unidade, a gestão do corpo é o tema no qual o autor mais se detém. Como afirma na página 78, "as regras da arte pugilística remetem a movimentos do corpo que só podem ser apreendidos completamente em ato". Somente através disso pode-se entender um pouco da pedagogia peculiar do boxe, que se faz pela repetição e imitação e que, paulatinamente, redefine um a um todos os parâmetros da existência do lutador. Disso resulta um saber prático, composto de esquemas corporais, emocionais, visuais e mentais, relacionado essencialmente a um processo rigoroso de educação do corpo, constantemente remodelado segundo exigências próprias ao campo.

Não é à toa que o autor assinala como indispensável ao conhecimento adequado do objeto a apreensão indígena da embriaguez sensorial do boxe, 
domínio no qual a teoria tem pouca utilidade, uma vez que a compreensão pelo corpo ultrapassa e precede a compreensão visual e mental (p. 89). Ao dialogar com as questões das ciências sociais, oriundas tanto de correntes mais clássicas, como a teoria dos jogos, quanto das questões da sociologia do esporte atuais, Wacquant marca o lugar da especificidade do fazer antropológico, especialmente a partir da etnografia ou a relação entre a pesquisa empírica e a reflexão teórica. Sua posição no campo tem como base o "abandono", colocando em xeque antigos pressupostos que tentam focalizar racionalmente uma distinção entre o corporal e o mental, modos típicos de consciência que, segundo Wacquant, estão fora de propósito no universo do boxe, onde não há uma "razão raciocinante". Por isso, autor qualifica a aprendizagem bem-sucedida do boxe como um processo que se inculca de modo lento, um sensibilidade pugilística incorporada, feita da combinação de disposições quase antinômicas: pulsões e impulsos inscritos no mais profundo do indivíduo biológico no limite do cultural e do selvagem, modificada a cada instante pelo seu agente, embora não inacessível ao cálculo explícito da consciência individual (p. 119).

No segundo texto, "Uma noitada no Studio 104", o autor fala mais detidamente de dois anos de submersão intensa, descrevendo desde uma jornada e reuniões de boxe e festividades em bares do bairro ao comparecimento às etapas dos torneios, lutas e comemorações sociais. Sua contribuição aqui é nos conduzir aos meandros, por assim dizer, da realidade nua e crua dos pugilistas, seus treinos prolongados, as penúrias enfrentadas como moradores do gueto negro, as privações familiares, sexuais e alimentares vividas por esses seres, suas alegrias e êxtases nas conquistas diárias, enfim, a uma descrição densa da história da vida privada do lutador, vivenciando batizados, casamentos e funerais. $\mathrm{O}$ autor assinala mais uma vez que realmente estava lá. A riqueza do capítulo repousa nas inúmeras transcrições de trechos de seu diário de campo. Surpreendente o modo como pôde captar o panorama, os antecedentes e o contexto de onde emergem os pontos de vistas desses homens e os conhecimentos práticos acerca desse ofício. Trata-se de um testemunho de um pesquisador que participou do cotidiano da Rua 63, a ponto de lançar dúvidas sobre sua verdadeira missão ali como sociólogo. É o que demonstra o comentário de seu companheiro de treino duro (sparring) Curtis, que se espanta ao ver o pesquisador agindo como tal, tomando notas em seu diário e usando o gravador: "um dia, você vai se suicidar, Louie, porque você escreve demais". Na noitada do bar Studio 104, Wacquant pôde também compartilhar um contexto cultural específico da 
sociabilidade da classe popular afro-americana, com direito a conversas furtivas sobre mulheres, brigas, boxe, prisão, futebol americano e rap music, graças aos longos anos de campo, o que forneceu os fios com os quais teceu a camaradagem com os companheiros desse circuito.

O terceiro, "Busy Louie", descreve passo a passo sua preparação e a apresentação na temporada de 1990, em um campeonato importante, o Chicago Golden Gloves. Para esse evento, nosso sociólogo boxeador condicionou, ao longo de sete semanas, suas costelas e sua mente para agüentar os treinos duros, deixando que seus parceiros o golpeassem centenas de vezes. Segundo Wacquant, só um raro estado de corpo e mente permite que um ser humano empreenda tal atividade. Não se consegue isto por um simples estado de vontade. Só isso o fez compreender o que realmente significa preparar-se para um combate: dia após dia, submetendo-se aos rigores intratáveis e incontornáveis do treinamento, o que pode ser comparado a um verdadeiro ritual de mortificação, ao modo de uma religião em que o sacrifício é a palavra de ordem (p. 272). O resultado dessa luta de muitos meses não significa propriamente o final, mas um desafio à imaginação, à originalidade da pesquisa, e enquanto modelo de prática etnográfica. Em suas palavras, "o pertencimento ao gym é a marca tangível da aceitação em uma confraria viril que permite que a pessoa se destaque do anonimato da massa e atraia a atenção da sociedade local".

\section{NOTAS}

1 Doutora em Saúde Coletiva pelo Instituto de Medicina Social da UERJ.

2 Ver Wacquant, L. Os três corpos do Lutador Profissional. In: LINS, D. (Org.). A dominação masculina revisitada. Campinas: Papirus, 1998.

3 Wilson, J. The truly disadvantaged. Chicago: The University of Chicago Press, 1987.

4 Retomando a noção aristotélica de hexis, convertida pela escolástica em habitus, Bourdieu busca enfatizar com o habitus o "primado da razão prática", o princípio do "conhecimento adquirido" que o conceito comporta: "o habitus, a hexis, indica uma disposição incorporada, quase postural (...) o lado ativo do conhecimento prático que a tradição materialista, sobretudo com a teoria do reflexo tinha abandonado" (Bourdieu,1989, p. 61). 